\title{
Setting up a Company Performance Measurement Methodology for the Aerospace Industry: Deduction from the Automotive Industry
}

\author{
Wouter W.A. Beelaerts van Blokland ${ }^{1}$, Nicolaas H. Elferink ${ }^{2}$ and Frank M. van der Zwan ${ }^{3}$ \\ Delft University of Technology, 2629 HS Delft, The Netherlands
}

Theories on value creation, co-innovation and co-development and lean enterprise have gained in popularity in recent times. This research has taken aim at extending the investigation on how to quantify companies' capabilities in creating value for their stakeholders. A theoretical framework was adopted to build the performance measurement method on. This framework identifies five performance indicators of company performance: competition performance, financial performance, manufacturing capability, innovation capability and supply chain relationships. Due to the limited availability of data in aviation industry, use was made of data from the automotive industry. Data from 33 automotive OEMs was collected from which a set of variables was constructed. The behavior and relations of these variables were investigated and eventually five variables were selected, one for each performance indicator. Using multiple regression techniques weight factors were determined for each variable and a linear model was constructed, expressing a company performance index. This linear model allows assessing and comparing the performance of different companies over an arbitrary period of time. For the automotive OEMs this was qualitatively shown to work. The model was then adapted to fit the aerospace OEMs and the weight factors were recalculated. Unfortunately, due to the limited availability of data for aerospace OEMs, it was not possible to obtain great insights into the behavior and relations of the variables for these aerospace companies. Moreover, the weight factors of the linear model could not be determined with much accuracy. To solve this, it is recommended that for future research data collection continues and that in some years the research is redone with more data, allowing statistical analysis to be able to detect smaller effects.

\section{Nomenclature}

$I_{p} \quad=$ performance index

$T / C_{\text {Norm }}=$ normalized turnover per employee

$S P_{\text {Norm }}=$ normalized share price

$T_{\text {Norm }}=$ normalized turnover

$V / C_{N o r m}=$ normalized number of verhicles produced per employee

$R \& D / C_{\text {Norm }}=$ normalized $\mathrm{R} \& \mathrm{D}$ expenditure per employee

\section{Introduction}

T $\mathrm{N}$ recent times theories on value creation, co-innovation and co-development and lean enterprise have gained 1 popularity among researchers. Beelaerts van Blokland, Fiksiński, Amoa and Santema ${ }^{2,3,5}$ have made steps towards integrating these theories and quantifying them. The result is the concept of the 3C-model, accompanied by a set of three 3C-metrics to quantify it. Still, the quantification efforts performed up to now deserve more research, which is what this research will aim itself at. Before further discussing the research goal, it is important to first review the relevant existing literature. Each of the four theories mentioned above, value creation, co-innovation and codevelopment, lean enterprise and the 3C-model will be discussed subsequently.

${ }^{1}$ Lecturer SCM and Entrepreneuring, Air Transport \& Operations, Delft University of Technology, Kluyverweg 1, 2628 HS Delft, The Netherlands, email: w.w.a.beelaertsvanblokland@ @udelft.nl, AIAA senior member.

${ }^{2}$ MSc student, Air Transport \& Operations, Delft University of Technology, Kluyverweg 1, 2628 HS Delft, The Netherlands.

${ }^{3}$ Assistant Professor Aviation, Air Transport \& Operations, Delft University of Technology, Kluyverweg 1, 2628 HS Delft, The Netherlands, email: f.m.vanderzwan@tudelft.nl, AIAA senior member.

1

American Institute of Aeronautics and Astronautics 


\section{A. Value Creation}

Parasuraman, Zeithaml and Berry ${ }^{17}$ define customer value as "the subjective opinion of the customer as to what extent the provided product and service package meets his/her expectations". According to Gelei ${ }^{8}$, from a company's viewpoint, customer value is created when the profit made from selling the product and/or service exceeds the total cost of producing and delivering it. In recent times, value creation has transformed. A model of mass production and "market push" is replaced by a model based on customer demand pulling value through the supply chain. Customer needs are taken into account throughout the development and production process and hence the customer can now be seen as a co-creator of value ${ }^{18}$. Research on this topic has been extensive. Zhang and $\mathrm{Chen}^{26}$ found that taking customers' needs into account from the beginning has a positive influence on the adherence of the final product to the customers' needs and that this leads the company to have a larger competitive advantage. Harmsen and Jensen ${ }^{11}$ and Gelei ${ }^{8}$ go further than that and state that focusing more on the customer is indispensable for a company to survive.

\section{B. Co-Innovation and Co-Development}

Whereas customer input allows the company to produce better products, from a customer's viewpoint, the actual creation of this value occurs within the company and its supply chain. Within the complete supply chain, the company has two goals to achieve successful co-innovation and co-development partnerships with their suppliers. These are 'value creation' and 'value claiming ' ${ }^{6,22}$. The idea is to engage in cooperative relationships with suppliers, giving opportunities that might have been unavailable to either of the partners had they not partnered'. In the end, it all comes down to letting suppliers do what they are best at, improving product quality and functionality, reaping the financial benefits and improved profitability and sharing the gains. The advantages are twofold ${ }^{1}$. Firstly, there are advantages for the product itself; reduced time to market, reduced development costs and improved product quality ${ }^{5}$. Secondly, the advantages for the company are that there is a positive impact on its knowledge development and that it can focus more on its own core competences ${ }^{10}$.

\section{Lean Enterprise Theory}

The cooperation with customers and suppliers are also captured in the concept of lean supply ${ }^{12}$. Womack, Jones and $\operatorname{Roos}^{24}$ and Womack and Jones ${ }^{23}$ describe this as the successor to the mass production system. The lean philosophy originates from Toyota in Japan, but is now widespread, particularly in the automotive industry ${ }^{24}$. It is described as "a way to do more and more with less and less - less human effort, less equipment, less time and less space - while coming closer and closer to providing customers with exactly what they want" ${ }^{\prime 2}$. Beelaerts van Blokland, Fiksiński, Amoa and Santema ${ }^{5}$ state "lean thinking places 'optimizing the total value' instead of 'minimizing the cost' as the main goal". The concept of lean is based on five principle; value specification, value streams, flow, customer pull and perfection ${ }^{23}$. Much of the improvement it can bring stems from the elimination of waste in the system. In customer relations and the lean supply chain this means that transparency is an important prerequisite, allowing for clear and honest communication that avoids such problems as the "bullwhip effect" ${ }^{13}$ and allows principle such as Just-in-Time (JIT) supply to function properly ${ }^{24}$.

\section{The 3C-Model and 3C-Metrics}

The 3C-model is the result of the work done by Beelaerts van Blokland, Fiksiński, Amoa and Santema ${ }^{2,3,5}$, which has aimed at integrating these theories into one theory of value creation. The combined performance on each of three 'C's' is seen as a positive driver for value creation. The three C's are gives as 'continuation', 'conception' and 'configuration', together driving "better, cheaper, faster innovation". Continuation pertains to the adherence of products to customer needs, thereby creating a competitive advantage for the company, resulting in improved financial results, which allow the company to continue its existence and new product development efforts. Conception is the process, taking customer needs as the input, of designing and developing those products that are of value to the customer. It is thus related to innovation. Finally, configuration is the way in which the supply chain is organized and how the partners cooperate. The $3 \mathrm{C}$-model advocates the sharing of innovation and production efforts and investments with supply chain partners, leading to higher gains for all.

Beelaerts van Blokland et al. ${ }^{5}$ propose three metrics, one to quantify each of the three C's. Each of these metrics is a per-capita, or per-employee, metric. The reason for this is twofold. Firstly, by using a 'per employee' basis, the model recognizes the employee as the primary source of value creation within a company. Secondly, by dividing by the number of employees, metrics can fairly be compared between different companies of different sizes. Beelaerts van Blokland et al. ${ }^{5}$ see profit as the result of satisfied customer needs, thereby proposing the profit per employee (P/C) as a suitable measure for continuation. For conception they coin the Research and Development 
expenses per employee $(\mathrm{R} \& \mathrm{D} / \mathrm{C})$ as a good metric. Finally, for the configuration they propose the turnover per employee (T/C). Earlier research by Beelaerts van Blokland, Bulato, Elferink and Santema ${ }^{4}$ has investigated the behavior and relations of these $3 \mathrm{C}$-metrics over two sample of aerospace and automotive companies. It was found that the 3C-metrics correlate. However, the exact scientific meaning of the trends in and correlations between the $3 \mathrm{C}$-metrics deserves more exploration.

It is the aim of this research to jump into this gap, to integrate theories and concepts and to come to a new, not purely financial way to measure and express company performance. The intention is to work towards a method that can ultimately be applied to the aerospace industry, so that research on aerospace value creation and the performance of aerospace companies may be continued with a new valuable tool. The research question that this research will seek to answer is posed as: Can a new performance measurement methodology be developed, based on value creation, co-innovation and lean enterprise theory, that will allow the assessment of aerospace companies' health from a value creation, an engineering and a financial point of view?

It is important to note that this thus means the research will look for a quantitative method to measure company performance, not only from a financial viewpoint, but also with a value creation and engineering eye. Furthermore, the intention is to make this method usable by basically anyone, without the need for detailed, in-house company information or data.

\section{Methodology}

In order to achieve this goal, use will be made of data from publicly available annual reports to construct a set of variables that are believed to be able to provide insights on different aspects of company performance. Although the intention is to develop the model for use in the aerospace industry, most of the research will not be using data from aerospace companies. The reason for this is because there are only a few aircraft manufacturers in the world that are publicly owned, whereas there are many publicly owned automotive OEMs in the world. Therefore there is much more data available for automotive OEMs and because of that, the main chunk of research will be performed using automotive data, after which the results will be translated for aerospace application. Research by Tseng, Chiu and $\mathrm{Chen}^{20}$ has identified five indicators, or "pillars" of company performance. These are competition performance, financial performance, manufacturing capability, innovation capability and supply chain relationships. Good performance on all of these should span up to good performance of the whole company. The idea is to propose one or more variables for each of these performance pillars. Based on a series of analyses, a selection will be made of one variable per performance pillar, from which a linear model can be constructed. This linear model then has the power to assess the performance of a company, taking views from more than just a financial viewpoint. Table 1 specifies which variables are proposed for each of the performance pillars. For some variables also the source is indicated. The other variables will be discussed below.

\begin{tabular}{|l|l|l|}
\hline Performance Indicator & Variables & Source \\
\hline Competition Performance & Sales growth rate $(\Delta \mathrm{T})$ & Tseng et al. $^{20}$ \\
\hline & Turnover $(\mathrm{T})$ & \\
\hline Financial Performance & Market share $(\mathrm{MS})$ & Tseng et al. $^{20}$ \\
\hline Manufacturing Capability & Share price $(\Delta \mathrm{SP})$ & Tseng et al. $^{20}$ \\
\hline & Profit per employee $(\mathrm{P} / \mathrm{C})$ & Tseng et al. $^{20}$ \\
\hline & Inventory turnover $(\mathrm{T} / \mathrm{I})$ & Murman et al. $^{15}$ \\
\hline Innovation Capability & Vehicles per employee (V/C) & \\
\hline & R\&D efficiency (P/R\&D) & Tseng et al. $^{20}$ \\
\hline Supply Chain Relationships & Turnover per employee (T/C) & Beelaerts van Blokland $^{3}$ \\
\hline & Profit leverage (T/P) & \\
\hline
\end{tabular}

Table 1: The proposed research variables

American Institute of Aeronautics and Astronautics 
Table 1 does not indicate a source for three of the proposed variables. These variables have been found through the following reasoning. First of all, the turnover $(\mathrm{T})$ is taken along for statistically practical reasons, since it might behave in a more stable way than the sales growth rate. The number of sold vehicles per employee (V/C) is a replacement variable for the throughput time, proposed by Murman et al. (2002). The number of vehicles sold in a year is basically a measure of the output rate, which is an inverse measure of the throughput time. For comparability reasons, the number of vehicles was then divided by the number of employees, so that it is also a measure of employee productivity.Finally, the profit leverage (T/P) is deduced from earlier work by Beelaerts van Blokland et $\mathrm{al}^{3,5}$, who have defined the product multiplier (PMP) as a governing metric for configuration on a product level. It is defined as the total product value divided by the company's own added value to a product. It is thus also a measure of the amount of production outsourced to suppliers. This metric has been converted to an organizational level to obtain the turnover per profit $(\mathrm{T} / \mathrm{P})$ variable. The turnover is the total value produced and claimed by the supply chain, whereas the profit is that part of the total value that is claimed by the focal company.

A sample of 33 automotive OEMs was selected based on OICA ${ }^{16}$, which presents a list of the world's largest automotive manufacturers. From this list and the authors own knowledge of the automotive industry, in the end 33 companies were found to issue their own annual reports publicly, see Table 2. Together, the sample group accounts for more than 81 percent of the total global vehicle production. Therefore, it is believed that the sample is more than sufficiently large to speak for the whole automotive industry. The sample includes both carmakers and truck builders. In later stages of the research these two have been split up and were analyzed separately.

\begin{tabular}{|l|l|l|}
\hline Ashok Leyland & General Motors & Porsche \\
\hline Audi & Great Wall & PSA \\
\hline BMW & Hino Motors & Renault \\
\hline Brilliance & Honda & Scania \\
\hline BYD & Isuzu & Škoda \\
\hline Daihatsu & MAN & Spyker \\
\hline Daimler & Mazda & Suzuki \\
\hline Fiat & Mitsubishi & Tata \\
\hline Ford & Navistar International & Toyota \\
\hline Fuji Heavy Industries & Nissan & Volkswagen \\
\hline GAZ & PACCAR & Volvo \\
\hline
\end{tabular}

Table 2: The automotive OEMs included in the research sample

Annual reports were obtained from companies' corporate websites and the US Securities and Exchange Commission $^{21}$. Furthermore, request e-mails were sent out to all companies to ask for them to send in additional annual reports. Roughly three weeks after this first request e-mail a reminder was sent. In total about half of the companies asked replied and contributed by sending in one or more additional annual reports. A few companies, Daihatsu, Fuji Heavy Industries, Hino Motors and Suzuki, could not be reached.

For all 33 companies, all required data was collected from their annual reports to construct all the variables presented in Table 1, for as far back as 1980 if possible. Furthermore, additional data was collected from WRDS ${ }^{25}$. For some companies, mostly German companies, data is available for the full range of 1980 to 2008. For other companies less data could be obtained, sometimes even for only two financial years (such as Suzuki).

This fact makes that there is a significant asymmetry in the available data, which must be noted when considering the results of this research. Some companies, such as Daimler and Fiat, operate both as a carmaker and as a truck builder. These companies were analyzed in both categories and their market share and V/C data was collected based either on only their car making activities or on their truck making activities. Finally, the market share could only be approximated. This was done by dividing the total number of sold vehicles for a company in a certain financial year by the total number of produced vehicles (trucks or cars) in that year, found from OICA ${ }^{16}$. 


\section{Analysis}

\section{A. Bivariate Correlation Analysis}

The first step into the analysis is the assessment of bivariate correlations between all of the variables proposed. This is to provide an insight into the relations existing between the variables.

It was found that both the assumption of normality and the assumption of homogeneity of variance are violated by the data set and hence used must be made of non-parametric correlation tests; Spearman's Rho ${ }^{7}$. First, however, correlations were plotted using a correlation scatter matrix shown in Fig. 1 below, which led to the discovery that carmakers and truck builders exhibit different characteristics.

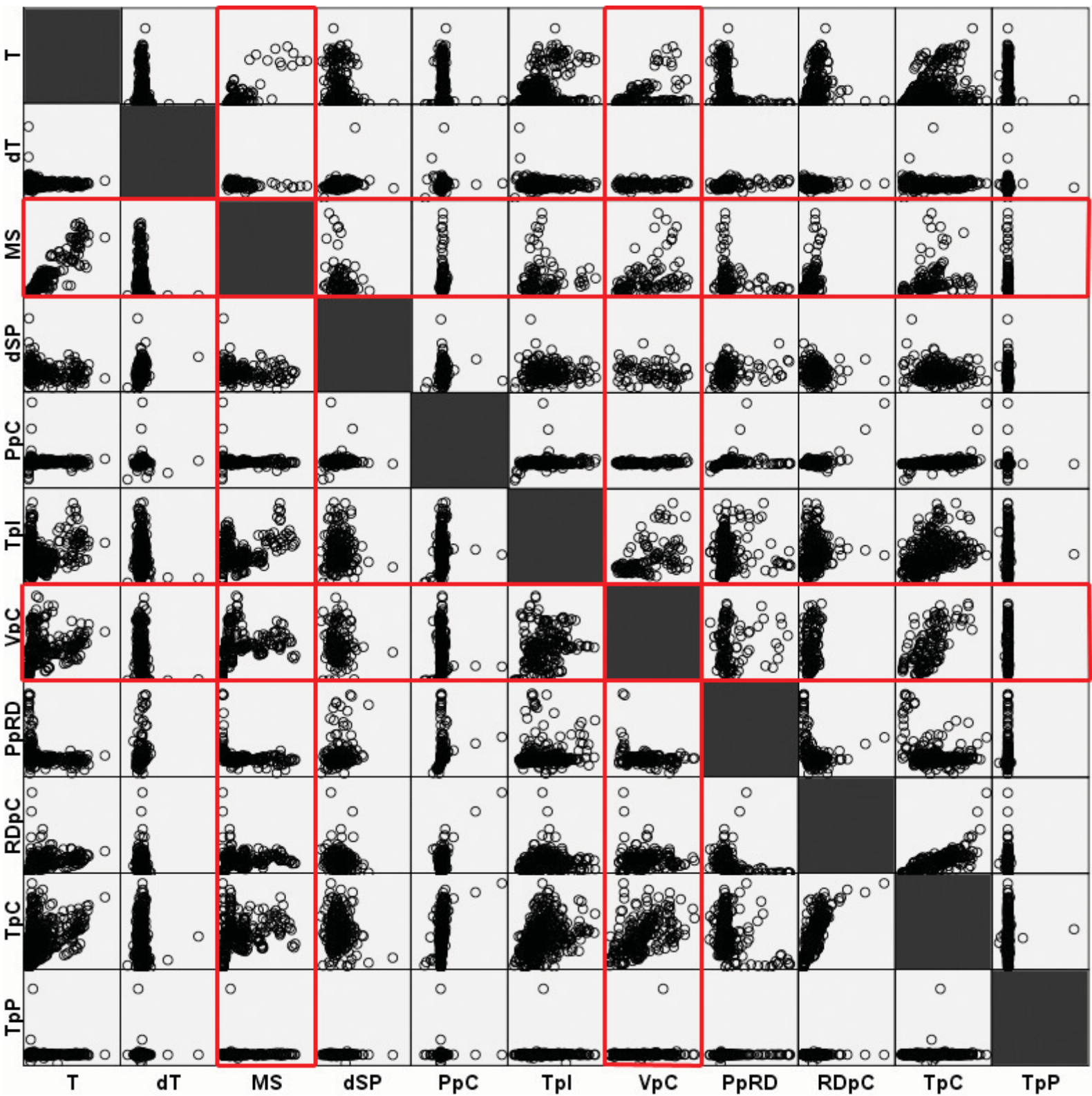

Figure 1: Correlation scatter matrix (lower left half are carmakers, top right half are truck builders)

Note, regarding only those fields that are within the red boxes, that the top right half of the figure corresponds to the truck builders, whereas the lower left half plots the correlations for carmakers. In this figure, one can clearly see, 
for example for the correlation between $\mathrm{T} / \mathrm{C}$ and $\mathrm{P} / \mathrm{R} \& \mathrm{D}$, that two lines are formed, corresponding to carmakers and truck builders.

Next, for the carmakers and truck builders the correlations were quantitatively assessed, the results of which are given in Table 3 and Table 4 below.

\begin{tabular}{|c|c|c|c|c|c|c|c|c|c|c|c|}
\hline & $\mathrm{T}$ & MS_LV & $\mathrm{P} / \mathrm{C}$ & $\mathrm{T} / \mathrm{I}$ & $\mathrm{LV} / \mathrm{C}$ & $\mathrm{P} / \mathrm{R} \& \mathrm{D}$ & $\mathrm{R} \& \mathrm{D} / \mathrm{C}$ & $\mathrm{T} / \mathrm{C}$ & $\mathrm{T} / \mathrm{P}$ & $\Delta \mathrm{T}$ & $\Delta \mathrm{SP}$ \\
\hline $\mathrm{T}$ & & & & & & & & & & & \\
\hline MS_LV & $\begin{array}{l}+ \\
0.880\end{array}$ & 18 & & & & & & & & & \\
\hline $\mathrm{P} / \mathrm{C}$ & $\begin{array}{l}+ \\
0.042\end{array}$ & $\begin{array}{l}+ \\
0.002\end{array}$ & & & & & & & & & \\
\hline $\mathrm{T} / \mathrm{I}$ & $\begin{array}{l}+ \\
0.023\end{array}$ & $\begin{array}{l}+ \\
0.035\end{array}$ & $\begin{array}{l}+ \\
0.054\end{array}$ & & & & & & & & \\
\hline $\mathrm{LV} / \mathrm{C}$ & $\begin{array}{l}+ \\
0.144\end{array}$ & $\begin{array}{l}+ \\
0.151\end{array}$ & $\begin{array}{l}+ \\
0.007\end{array}$ & $\begin{array}{l}+ \\
0.065\end{array}$ & & & & & & & \\
\hline P/R\&D & $\begin{array}{l}- \\
0.080\end{array}$ & $\begin{array}{l}- \\
0.095\end{array}$ & $\begin{array}{l}+ \\
0.468\end{array}$ & $\begin{array}{l}+ \\
0.067\end{array}$ & $\begin{array}{l}- \\
0.009\end{array}$ & & & & & & \\
\hline $\mathrm{R} \& \mathrm{D} / \mathrm{C}$ & $\begin{array}{l}+ \\
0.141\end{array}$ & $\begin{array}{l}+ \\
0.064\end{array}$ & $\begin{array}{l}+ \\
0.233\end{array}$ & $\begin{array}{l}+ \\
0.071\end{array}$ & $\begin{array}{l}+ \\
0.005\end{array}$ & $\begin{array}{l}- \\
0.015\end{array}$ & & & & & \\
\hline $\mathrm{T} / \mathrm{C}$ & $\begin{array}{l}+ \\
0.150\end{array}$ & $\begin{array}{l}+ \\
0.085\end{array}$ & $\begin{array}{l}+ \\
0.277\end{array}$ & $\begin{array}{l}+ \\
0.167\end{array}$ & $\begin{array}{l}+ \\
0.310\end{array}$ & $\begin{array}{l}+ \\
0.000\end{array}$ & $\begin{array}{l}+ \\
0.687\end{array}$ & & & & \\
\hline $\mathrm{T} / \mathrm{P}$ & $\begin{array}{l}- \\
0.002\end{array}$ & $\begin{array}{l}+ \\
0.014\end{array}$ & $\begin{array}{l}- \\
0.031\end{array}$ & $\begin{array}{l}+ \\
0.000\end{array}$ & $\begin{array}{l}+ \\
0.057\end{array}$ & $\begin{array}{l}- \\
0.158\end{array}$ & $\begin{array}{l}- \\
0.021\end{array}$ & $\begin{array}{l}+ \\
0.000\end{array}$ & & & \\
\hline$\Delta \mathrm{T}$ & & $\begin{array}{l}- \\
0.075\end{array}$ & $\begin{array}{l}+ \\
0.056\end{array}$ & $\begin{array}{l}+ \\
0.000\end{array}$ & $\begin{array}{l}- \\
0.015\end{array}$ & $\begin{array}{l}+ \\
0.171\end{array}$ & $\begin{array}{l}- \\
0.003\end{array}$ & $\begin{array}{l}- \\
0.000\end{array}$ & $\begin{array}{l}- \\
0.007\end{array}$ & & \\
\hline$\Delta \mathrm{SP}$ & $\begin{array}{l}- \\
0.012\end{array}$ & $\begin{array}{l}- \\
0.020\end{array}$ & $\begin{array}{l}+ \\
0.037\end{array}$ & $\begin{array}{l}+ \\
0.001\end{array}$ & $\begin{array}{l}- \\
0.018\end{array}$ & $\begin{array}{l}+ \\
0.034\end{array}$ & $\begin{array}{l}- \\
0.003\end{array}$ & $\begin{array}{l}- \\
0.001\end{array}$ & $\begin{array}{l}- \\
0.000\end{array}$ & $\begin{array}{l}+ \\
0.054\end{array}$ & \\
\hline
\end{tabular}

Table 3: Correlations for car makers

Note that the numerical values within each cell are the $\mathrm{R}^{2}$-values of the corresponding correlation, thus providing a measure of how strong the correlation is. The plus or minus sign indicates the direction of correlation (positive or negative). Finally, the color indicates the significance of the correlation found. A dark green cell indicates the corresponding correlation was significant at the $\mathrm{p} \leq 0.01$ level and a light green cell indicates it was significant at $\mathrm{p} \leq 0.05$. A white cell shows a correlation that was not significant.

It is important to make sure that the variable correlations between the performance variables provide a strong predicting ability of these performance variables. The foregoing analysis has shown that not all variables comply with this requirement. Firstly, T/P has, where significant, shown mostly negative correlations, which is precisely opposite from what one would expect if it were indeed a good measure of the supply chain relationships indicator of performance. Apparently then T/P is not an accurate variable to measure company performance, since the analysis has shown that most other variables vary inversely with T/P. In other words, a low T/P predicts high values of most of the other variables.

The explanation for this is likely to be along the lines of the following. This research' theoretical reasoning was that T/P quantifies how much of the total product value is added by the company's suppliers. However, T/P basically is the inverse of the profit margin $(\mathrm{P} / \mathrm{T})$, which is a frequently used company performance indicator. In short: T/P is not similar to the product level's production multiplier (PMP) ${ }^{5}$ on an organizational level. Rather, it is 
simply the inverse of the profit margin, which explains why it correlates negatively to most other research variables. For this reason, T/P will at this point be discarded in the research.

\begin{tabular}{|c|c|c|c|c|c|c|c|c|c|c|c|}
\hline & $\mathrm{T}$ & MS_HV & $\mathrm{P} / \mathrm{C}$ & $\mathrm{T} / \mathrm{I}$ & $\mathrm{HV} / \mathrm{C}$ & $\mathrm{P} / \mathrm{R} \& \mathrm{D}$ & $\mathrm{R} \& \mathrm{D} / \mathrm{C}$ & $\mathrm{T} / \mathrm{C}$ & $\mathrm{T} / \mathrm{P}$ & $\Delta \mathrm{T}$ & $\Delta \mathrm{SP}$ \\
\hline $\mathrm{T}$ & & & & & & & & & & & \\
\hline MS_HV & $\begin{array}{l}+ \\
0.327\end{array}$ & & & & & & & & & & \\
\hline $\mathrm{P} / \mathrm{C}$ & $\begin{array}{l}+ \\
0.036\end{array}$ & $\begin{array}{l}+ \\
0.114\end{array}$ & & & & & & & & & \\
\hline $\mathrm{T} / \mathrm{I}$ & $\begin{array}{l}- \\
0.094\end{array}$ & $\begin{array}{l}+ \\
0.077\end{array}$ & $\begin{array}{l}+ \\
0.215\end{array}$ & & & & & & & & \\
\hline $\mathrm{HV} / \mathrm{C}$ & $\begin{array}{l}+ \\
0.092\end{array}$ & $\begin{array}{l}+ \\
0.255\end{array}$ & $\begin{array}{l}+ \\
0.051\end{array}$ & $\begin{array}{l}+ \\
0.284\end{array}$ & & & & & & & \\
\hline $\mathrm{P} / \mathrm{R} \& \mathrm{D}$ & $\begin{array}{l}- \\
0.197\end{array}$ & $\begin{array}{l}- \\
0.085\end{array}$ & $\begin{array}{l}+ \\
0.376\end{array}$ & $\begin{array}{l}+ \\
0.155\end{array}$ & $\begin{array}{l}+ \\
0.000\end{array}$ & & & & & & \\
\hline $\mathrm{R} \& \mathrm{D} / \mathrm{C}$ & $\begin{array}{l}+ \\
0.324\end{array}$ & $\begin{array}{l}+ \\
0.228\end{array}$ & $\begin{array}{l}+ \\
0.026\end{array}$ & $\begin{array}{l}+ \\
0.000\end{array}$ & $\begin{array}{l}+ \\
0.038\end{array}$ & $\begin{array}{l}- \\
0.279\end{array}$ & & & & & \\
\hline $\mathrm{T} / \mathrm{C}$ & $\begin{array}{l}+ \\
0.078\end{array}$ & $\begin{array}{l}+ \\
0.301\end{array}$ & $\begin{array}{l}+ \\
0.371\end{array}$ & $\begin{array}{l}+ \\
0.243\end{array}$ & $\begin{array}{l}+ \\
0.382\end{array}$ & $\begin{array}{l}- \\
0.003\end{array}$ & $\begin{array}{l}+ \\
0.341\end{array}$ & & & & \\
\hline $\mathrm{T} / \mathrm{P}$ & $\begin{array}{l}+ \\
0.011\end{array}$ & $\begin{array}{l}+ \\
0.004\end{array}$ & $\begin{array}{l}- \\
0.061\end{array}$ & $\begin{array}{l}- \\
0.024\end{array}$ & $\begin{array}{l}+ \\
0.007\end{array}$ & $\overline{0}-\overline{0} 88$ & $\begin{array}{l}+ \\
0.018\end{array}$ & $\begin{array}{l}- \\
0.004\end{array}$ & & & \\
\hline$\Delta \mathrm{T}$ & & $\begin{array}{l}- \\
0.046\end{array}$ & $\begin{array}{l}+ \\
0.018\end{array}$ & $\begin{array}{l}+ \\
0.035\end{array}$ & $\begin{array}{l}+ \\
0.012\end{array}$ & $\begin{array}{l}+ \\
0.067\end{array}$ & $\begin{array}{l}- \\
0.014\end{array}$ & $\begin{array}{l}+ \\
0.000\end{array}$ & $\begin{array}{l}- \\
0.009\end{array}$ & & \\
\hline$\Delta \mathrm{SP}$ & $\begin{array}{l}- \\
0.020\end{array}$ & $\begin{array}{l}- \\
0.052\end{array}$ & $\begin{array}{l}+ \\
0.000\end{array}$ & $\begin{array}{l}+ \\
0.004\end{array}$ & $\begin{array}{l}- \\
0.056\end{array}$ & $\begin{array}{l}+ \\
0.037\end{array}$ & $\begin{array}{l}- \\
0.045\end{array}$ & $\begin{array}{l}- \\
0.010\end{array}$ & $\begin{array}{l}- \\
0.014\end{array}$ & $\begin{array}{l}+ \\
0.155\end{array}$ & \\
\hline
\end{tabular}

Table 4: Correlations for truck builders

Secondly, the two "delta variables" ( $\Delta \mathrm{T}$ and $\Delta \mathrm{SP}$ ) should be looked at. Both correlate only to a small number of other variables and, moreover, they often correlate negatively. The probable reason for this is that because they are change-variables, they behave rather unstable. In any case, the metrics' unstable behavior makes them rather unsuitable for continued use in the research. In the remainder of the research $\Delta \mathrm{T}$ will be discarded, because the absolute turnover can take over its "task". As for $\Delta \mathrm{SP}$, the absolute share price (SP) can be used when looking at individual companies. Later on in this research, both $\mathrm{T}$ and $\mathrm{SP}$ will be normalized and hence they can be employed to replace $\Delta \mathrm{T}$ and $\Delta \mathrm{SP}$ respectively.

Focusing on the $3 \mathrm{C}$-metrics by Beelaerts van Blokland ${ }^{3}$ for a moment, T/C vs. R\&D/C also shows a particularly high $\mathrm{R}^{2}$-value; 68.7 percent. This was already found by Beelaerts van Blokland et al. ${ }^{4}$. They explained this by considering the fact that many automotive OEMs set their R\&D budgets as a fixed percentage of the total turnover, thereby setting an inherent relationship between the two variables. Also the other 3C-metric combinations can be looked at. Also T/C vs. P/C and R\&D/C vs. P/C show rather high $\mathrm{R}^{2}$-values; 27.7 percent and 23.3 percent respectively. In turn the $3 \mathrm{C}$-metrics are also correlated significantly to most of the other proposed variables. This suggests they indeed have something to say about value creation and company performance. However, the fact that also other variables show significant and strong correlations shows that the 3C-metrics are not the only metrics that can predict value creation and company performance.

Finally there's the profit per R\&D (P/R\&D). In both correlation analyses (carmakers and truck builders) it showed to be negatively correlated to a lot of the other variables. An explanation for this could be that P/R\&D does not actually measure the R\&D effectiveness, but rather merely the ratio of profit and R\&D, which decreases as R\&D increases. Companies spending more on R\&D than they gain from it on profit are penalized by this variable,

7

American Institute of Aeronautics and Astronautics 
whereas the increase in R\&D expenditures may still lead to an absolute gain in turnover and profit overall. As a result also $\mathrm{P} / \mathrm{R} \& \mathrm{D}$ will be discarded in the remainder of the research.

Summarizing, four variables will not be taken along in the upcoming research steps; T/P, $\Delta T, P / R \& D$ and $\Delta S P$. Therefore, the remainder of the research will be performed with the following variables:

- Turnover (T)

- Share price (SP)

- Market share cars/trucks

- Profit per capita (P/C)

- Inventory turnover (T/I)

- Cars/trucks per capita

- $\mathrm{R} \& \mathrm{D}$ per capita $(\mathrm{R} \& \mathrm{D} / \mathrm{C})$

- Turnover per capita (T/C)

\section{B. Filtering the Data}

The foregoing analysis was performed over the complete "cloud" of data, including all companies and data points. Before going on, it is important to filter the data cloud in order to take out "bad data" that distort the results. First of all, look at the financial performance pillar. In the foregoing it was found that the behavior of the change in share price $(\Delta \mathrm{SP})$ variable was too unstable to be of use to this research. However, $\Delta \mathrm{SP}$ was introduced as a replacement for the absolute share price (SP), because share price is by definition not a variable that can be compared between different companies, since a large part of a company's share price is somewhat arbitrarily determined when shares are issued. In the following, this research will look at companies individually and share price can be used as a variable again, as long as it is not compared between different companies. In short, the share price will be reintroduced as a variable for financial performance in this chapter. Now, for financial performance, innovation capability and supply chain relationships each only one variable remains. The intention is to have each pillar of company performance be represented by only one variable. For competition performance and manufacturing capability a selection still has to be made.

Considering the manufacturing capability indicator first, it was found by analyzing the data for companies individually that for many carmakers and truck builders $\mathrm{T} / \mathrm{I}$ is a variable that usually does not correlate significantly to many or all of the other variables. Recuperating that each of the variables is intended to express company performance for one of the five performance pillars, a variable that so consistently does not show significant correlation is one that does not behave consistent with the overall company performance and is thus not an accurate variable. Therefore, T/I should be discarded at this point in the research. It does not behave consistent enough to be able to provide meaningful information about company performance.

That then limits the candidate variables for the manufacturing capability aspect of performance to $\mathrm{P} / \mathrm{C}$ and V/C. Both can be seen as a measure of the output of a company and are thus a measure of productivity. For the carmakers it was found that for P/C 47.1 percent of the available correlations was found to be insignificant. For V/C this was only 29.3 percent. For the truck builders these figures were 35.4 and 31.8 percent respectively.

An insignificant correlation is basically caused because the behavior of the two respective variables over time is not consistent. More insignificance thus means more inconsistency in the behavior. It also means that no inferences can be made from such data. Thus, using the above found percentages it was assessed that V/C shows the most stable behavior in relation to the other (remaining) performance metrics, which makes it the better candidate to represent the manufacturing capability performance pillar for the carmakers.

Now, look at the competition performance pillar, for which both MS and T are still in the running. The carmaker and truck builder groups consistently show that turnover is the variable that behaves in the most stable way and is thus the better candidate to represent competition performance. It was striking to notice how bad market share would correlate to the other performance metrics, particularly considering that it is one of the most frequently used metrics to measure competition between companies. A possible cause for this unexpected behavior could be in the way market share figures were determined. By using total global production figures as the denominator in the global market share calculations for the companies, an inaccuracy is undoubtedly introduced. Although initially it was believed this error should be acceptable, since it is consistently introduced for all companies, it now seems this error was in fact not acceptable. Still, the turnover variable remains to represent the competition aspect of performance, so in the end there is no impact on the research results.

Apart from difference between variables, it was also shown there are differences between companies. For some companies, like Audi, (nearly) all variables correlate significantly and strongly, whereas for other companies, such as FHI, the exact opposite seems to be the case. Because insignificant correlations are a sign of instability of 
variables' behavior and because they do not provide the power to make a lot of inferences from, the aim of this section is to filter out those companies that show insignificant correlations between remaining variables (and thus show instable behavior of their performance variables). For the purpose of setting up the performance measurement model it is important to make use of data of only those companies that show significant correlations for all of the remaining variables. Looking first at the carmakers again, there are a number of companies that do not show insignificant correlations at all. These carmakers are Audi, Fiat, Porsche, PSA, Renault and Škoda. Similarly, the truck builders showing no insignificant correlations at all are Ashok Leyland, Fiat, Hino, MAN and PACCAR. Therefore, the data belonging to the six carmakers and five truck builders listed above will be used as input for building the performance measurement model.

\section{Setting up a Performance Measurement Methodology}

Before correlations can be properly analyzed, it must be noted that the share price (SP) and turnover (T) variables should first be normalized. For share price this is because, as was already mentioned, because share price in itself cannot be compared between different companies. Similarly, turnover, being an absolute variable, dependent on the company's size, cannot fairly be compared between companies either. By normalizing the variables' values, comparability can be assured. The other three variables, V/C, R\&D/C and T/C, have factually already been normalized through the division by the company's number of employees. Therefore these three variables do not require normalization per se. Still, because the performance measurement model to be developed is to measure performance from a set of linear equations, these variables will have to be normalized as well, so as to be sure the absolute value range (especially the difference thereof between variables) of a variable for a company has no influence on the outcome of the model. Therefore all variables were normalized by dividing their values in each financial year by the value of financial year 2004, since that was the first year for which all of the remaining companies had all required data available.

Given the aim of this research, at some point a switch must be made from pure research to definition of a model. As could already be seen from the bivariate correlation analysis, multicollinearity exists between the variables in this data set, which can be a problem to the accurate determination of each predictor variable's influence on an outcome variable when performing multiple regression analysis ${ }^{7}$. The solution to this would be to leave out several predictor variables that correlate to others, such that the remaining predictor variables no longer co-vary. In effect, this would mean that all outcome variables would be predicted by only one predictor. However, the aim of this research is to express a performance index that is influenced by all relevant variables. Therefore the choice was made not to employ a multiple regression analysis directly, but rather to use it as a way to determine five constants, one for each variable. These constants will be multiplied by their corresponding variable and then simply added up, yielding a linear equation that defines the final linear equation, defining the performance index. The advantage of such an approach is that all relevant variables can be taken into the model and that the theoretical relations between all variables are taken into account. For example, if the competition performance is a function of SP, V/C, R\&D/C and $\mathrm{T} / \mathrm{C}$ (all normalized), and these predictors all co-vary, then a company performing well on all of these predictors (which is a good thing in itself) will find itself with a higher competition performance influence on the final index than a company that performs less well. The disadvantage of this approach is that the results do not have any "physical" meaning, but can only be used for comparative analysis between companies. Finally, it should be noted that this research never speaks about causality. Rather, it focuses on the mutual relationships and predicting abilities of the variables.

The idea is to perform five multiple regression analyses, one per variable, where each time the other four variables are seen as predictor variables. Basically what such an analysis does is to find how much of the variation in the outcome variable can be explained from the variation in the set of predictor variables. Additionally, a multiple regression analysis can determine the influence of each predictor variable separately. However, because of the mentioned multicollinearity, this last thing cannot be done with accuracy in this research. In any case, the resulting R2-value of each multiple regression analysis will be used as a constant in the linear performance measurement equation for each respective performance variable. The result is a linear equation that determines a performance index. For the carmakers this equation is given as:

$$
\mathrm{I}_{\mathrm{P}}=\frac{0.731 \mathrm{SP}_{\mathrm{Norm}}+0.958 \mathrm{~T}_{\mathrm{Norm}}+0.740 \mathrm{~V} / \mathrm{C}_{\mathrm{Norm}}+0.681 \mathrm{R} \& \mathrm{D} / \mathrm{C}_{\mathrm{Norm}}+0.970 \mathrm{~T} / \mathrm{C}_{\mathrm{Norm}}}{4.080}
$$


The division by 4.080 (the sum of all five constants) assures that any company whose normalized data is input to the equation the performance index equals the value one in the base year. Similarly, for the truck builders the equation is found as:

$$
\mathrm{I}_{\mathrm{P}}=\frac{0.564 \mathrm{SP}_{\mathrm{Norm}}+0.933 \mathrm{~T}_{\mathrm{Norm}}+0.861 \mathrm{~V} / \mathrm{C}_{\mathrm{Norm}}+0.603 \mathrm{R} \& \mathrm{D} / \mathrm{C}_{\mathrm{Norm}}+0.959 \mathrm{~T} / \mathrm{C}_{\mathrm{Norm}}}{3.920}
$$

Having defined an equation that allows the calculation of a performance index value, for both the carmakers and the truck builders, it is now time to describe how this model is intended to be used. Basically, what the model allows to do is to compare the performance of different automotive companies over a period of at least one financial year, requiring a minimum of two financial years of available data. The idea is to normalize the values of the SP, T, V/C, $\mathrm{R} \& \mathrm{D} / \mathrm{C}$ and $\mathrm{T} / \mathrm{C}$ variables using the first year of the period under investigation as a base year, similar to the normalization process. In this base year the values of all variables will be equal to one for all companies, resulting in an $\mathrm{I}_{\mathrm{P}}$ value of one as well, thus providing an equal starting point for the comparison.

The performance measurement model does not make any statements about absolute levels of company performance, but rather it assesses changes in performance over a period of time. This is in line with the aim for it to be of particular use to investors and industry analysts. Those companies that show the fastest performance growth are of most interest to investors, since these are the companies that are expected to show the best share performance in tandem with that. Furthermore, by looking at change in performance, rather than at absolute performance levels, performance drops can also be more easily detected.

When one is looking for the performance (change) over a period of time, the normalized variable values at the end of the considered period should be inserted into the appropriate equation. Calculating $\mathrm{I}_{\mathrm{P}}$ per company should give a performance index for each company that is a measure of the performance relative to the base year. If the value of $I_{P}$ is lower than one, this means that, seen over all five performance pillars together, the company's performance was negative, meaning it is going backwards. If it is larger than one, the company has made progress relative to the base year. Different companies can be compared by comparing their respective $I_{P}$ values, where higher values are better.

\section{Illustrating the Model}

As a means of illustration, Figure 2 shows the performance index over two periods (2002-2007 and 2006-2007) for a group of carmakers. One can clearly see that between 2002 and 2007, Audi and Volkswagen made the largest performance

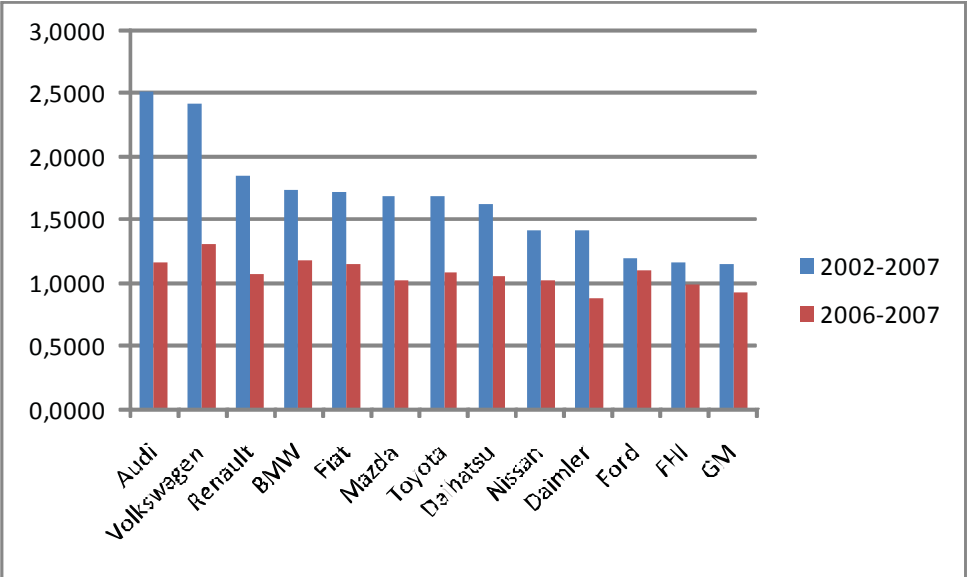

Figure 2. Car makers $\mathbf{I}_{\mathbf{p}}$ progression. Do note, however, that in the last year of that period Volkswagen's performance exceeded that of Audi. This is caused by the fact that it performed exceptionally well on the financial performance pillar; its share price performance was very high between 2006 and 2007. A possible cause to this could be related to the fact that Porsche had recently increased its ownership in the VW Group, which ultimately led to the bickering about ownership between the two companies, which was so extensively covered in the media. A set of "medium performers" follows at some distance. These are Renault, BMW, Fiat, Mazda, Toyota, Daihatsu, Nissan and Daimler. Although all companies have a positive performance index over the period 2002 to 2007, the last one of these medium performers, Daimler, shows, like FHI and GM, a performance index lower than one over 2006 to 2007, indicating its performance in that year was negative. For FHI and GM these results are genuine, in line with the fact that these companies have struggled over the last years. For Daimler this result may not be very fair, due to the fact that between 2006 and 2007 it divested its Chrysler division, which should have had an impact on the value of its variables. Lastly, note that Ford does not show an $\mathrm{I}_{\mathrm{P}}$-value of lower than one at all. Although one would say that this does not seem to be right due to the fact that Ford is one of the American "Big Three" that got into trouble in the recent financial crisis, one should consider that, firstly, the financial crisis had not set in yet in 2007 and, secondly, Ford, although it is not doing too well, was the only one of the Big Three who in the end did not require any government support due to the fact that it was not in a bad a shape as GM and Chrysler. 
Next, look at Figure 3 for the truck builders. Ashok Leyland is clearly the company whose performance improved most. Given the idea that this is an Indian company, operating in an emerging market, this is no surprise. The other truck builders follow at varying distances. Note how PACCAR and Volvo have shown a constant performance over the 2006 to 2007 period and that Hino and Daimler have actually shown a negative performance. Once again though, Daimler's figures may be somewhat skewed from the fact that between 2006 and 2007 it divested Chrysler.

\section{E. "Validation" of Results}

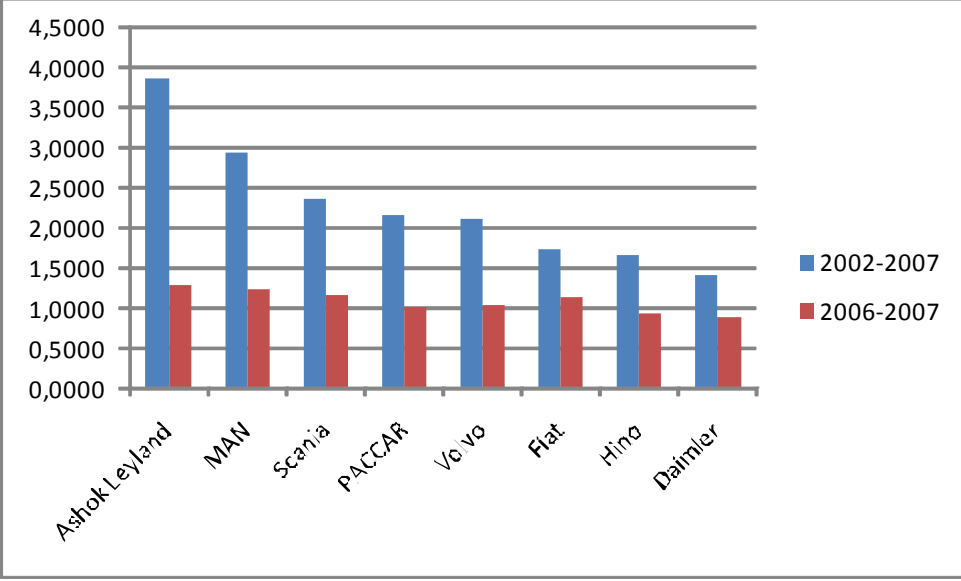

Figure 3. Truck builders $I_{p}$

Validation of results in the strict sense of the word is not something that can be done. To do this there would have to be some independent measure that performance index could be benchmarked against, showing that it yields the same or similar results as this alternative measure. Unfortunately, there is no such measure available. In fact, precisely the reason why this research was performed was to develop an integral performance measure to fill this gap. It is inherent to the fact that something integral, something new has been defined that its results are difficult to validate.

Still, there is some light that can be shed on this. Anyone who has followed the automotive news over the past years will know that some companies are in a considerably worse state that others. A financial crisis began in 2008, but even before then were some companies falling behind. Most notably these were the American Big Three companies, Ford, GM and Chrysler. At the same time, some other companies have done considerably better than the rest. Audi is one such company and also Volkswagen has been doing well, taking shares in Suzuki and Porsche and having stated it would be interested in taking over Alfa Romeo from Fiat. In fact, recently Volkswagen, now merged with Porsche, took over Toyota's position as largest carmaker in the world ${ }^{14}$.

Simultaneously, some would expect Toyota to be among the best performers as well. However, Fig. 2 clearly shows it is not, ranking somewhere halfway among the average performers. Now, this really is in line with recent signs on Toyota's performance. The Economist has recently published an article, in which it cites Mr. Akio Toyoda, Toyota's president, about how Toyota may face decline if it does not act ${ }^{19}$. In other words, the fact that Fig. 2 shows Toyota is only performing among the average performers does seem to reflect Toyota's problems that have recently come to light. As for the truck builders, it is no surprise that the pack that was investigated in Fig. 3 is led by a company from India, a rapidly developing economy. It is companies from such rapidly developing countries that exhibit the fastest performance growth and hence those are the companies with the highest $\mathrm{I}_{\mathrm{P}}$-values.

In short, although validation of the research results is not directly possible given the nature of the results, one can see that the performance model introduced seems to line up nicely with recent media coverage on automotive company performance. Still, there is also a possible weakness in the model that can be best seen by considering GM. In the model, an $\mathrm{I}_{\mathrm{P}}$ of more than one signifies a company has put effort into improving its performance and that these efforts were successful. However, GM is a company that has not been doing well for more than a few years now. Yet, still its $\mathrm{I}_{\mathrm{P}}$-value over the period 2002 to 2007 is above one, suggesting it too is making progress in performance strides, be it the least of all investigated companies. This is not what one would expect and the cause for this may be related to two things. Firstly, no correction was applied to the data for inflation. It could therefore be that inflation makes all companies' figures seem slightly better than they really are. Secondly, and more importantly, the direct influence of profit on the model's outcome was eliminated when V/C was chosen over P/C as a variable. Now it is only included indirectly through the share price, which was found to correlate strongly with P/C for most. It is already recommended that in future research this possible weakness is further examined and that corrective action is taken if needed. Solutions could be to increase the weight factor given to the share price variable in the model, or to reintroduce some kind of profit variable.

\section{F. Applying the Model to Aerospace OEMs}

The time has now come to use the knowledge gained to set up a similar company performance measurement model for the aerospace industry. The foregoing analysis of the automotive industry focused on its OEMs only. Earlier 
research by Beelaerts van Blokland et al. ${ }^{4}$ has already performed a comparison of the behavior of the $3 \mathrm{C}$-metrics between automotive OEMs and aerospace OEMs. The intention here is to keep the aerospace-automotive comparison as "pure" as possible, meaning that it will look at aerospace OEMs producing civil aircraft only.

As already stated, such companies are nowadays only a few in the world. To the author's knowledge there are only five publicly owned civil aircraft producers in the world, being Boeing, Bombardier, Dassault, EADS and Embraer. All of these companies, except Bombardier, are also engaged in the design and production of military aircraft. For these five companies as much data as possible was collected in the same way as was earlier described for the automotive OEMs. Now that the research is investigating aircraft manufacturers, a problem arises, with the V/C variable. Although, technically, one could simply measure the number of aircraft sold per employee, this would not be fair for two reasons. Firstly, all of the five companies are engaged in other than aircraft building activities. For example, Bombardier also makes trains, snow mobiles and all terrain vehicles (among other things), and Boeing also produces munitions and space systems (among many other things). Secondly, V/C would not be a measure validly comparable between companies. After all, the difference in required resources, efforts and labor force between the design and production processes of an Airbus A-380 and an Embraer EMB 120 can be imagined to be huge. To go short, a replacement variable should be picked for V/C to represent the manufacturing capabilities performance pillar. Referring back, $\mathrm{P} / \mathrm{C}$ was found to be the next best variable for the automotive OEMs and hence it will be adopted as the replacing variable for the aerospace OEMs. The explicit assumption here is that the variables proposed for the automotive industry also work for the aerospace OEMs. Therefore, the following will analyze the aerospace OEMs' turnover, share price, profit per capita, $R \& D$ expenditures per capita and turnover per capita.

The first step should be to investigate if the proposed variables correlate in a similar way as they did for the carmakers and truck builders. It is found that for the aerospace OEMs the proposed variables do not correlate significantly to each other, apart from a few exceptions, for the individual companies. This means that no conclusions can be drawn from this. However, it is important to note that only for Boeing an adequate amount of data points was available, meaning more than ten. For the other four companies only between seven and nine data points were available. This limited data availability makes that the correlation analysis is only able to detect the strongest of effects. Considerably more data would be needed to solve this problem. For now, the assumption will be made that the variables still have the power to provide insights on company performance, though this cannot be backed up with correlation results until more data is available.

In a similar way, the performance index equation for the aerospace OEMs is found to be:

$$
\mathrm{I}_{\mathrm{P}}=\frac{0.458 \mathrm{SP}_{\mathrm{Norm}}+0.267 \mathrm{~T}_{\text {Norm }}+0.034 \mathrm{~V} / \mathrm{C}_{\mathrm{Norm}}+0.101 \mathrm{R} \& \mathrm{D} / \mathrm{C}_{\mathrm{Norm}}+0.499 \mathrm{~T} / \mathrm{C}_{\mathrm{Norm}}}{1.359}
$$

This result is quite different than it was for the automotive OEMs. The highest constants (R2-values) shown are considerably lower, even lower than the lowest for the automotive OEMs. Two of the R2-values are in fact so low that they could not be termed significant (the ones for V/C and R\&D/C). Yet, this time this result cannot be blamed on a data shortage ( $\mathrm{N}=43$, where it was 33 and 45 for the carmakers and truck builders respectively). Rather, these results are likely to have arisen because the data could not be filtered.

Once again, the model found can be applied to the companies in the sample. Because 2004 is the earliest year for which all required data is available for all aerospace companies, performance of the five companies will be analyzed over the period 2004 to 2008. All companies have their financial year end around the same time, so this time incorporating crisis year 2008 does not make an unfair comparison.

As opposed to the illustration of the model for the automotive OEMs, this section will apply the model to all years between 2004 and 2008, also yielding a view of how company performance behaved during the period and not just over the period. The results of this are plotted in Figure 4.

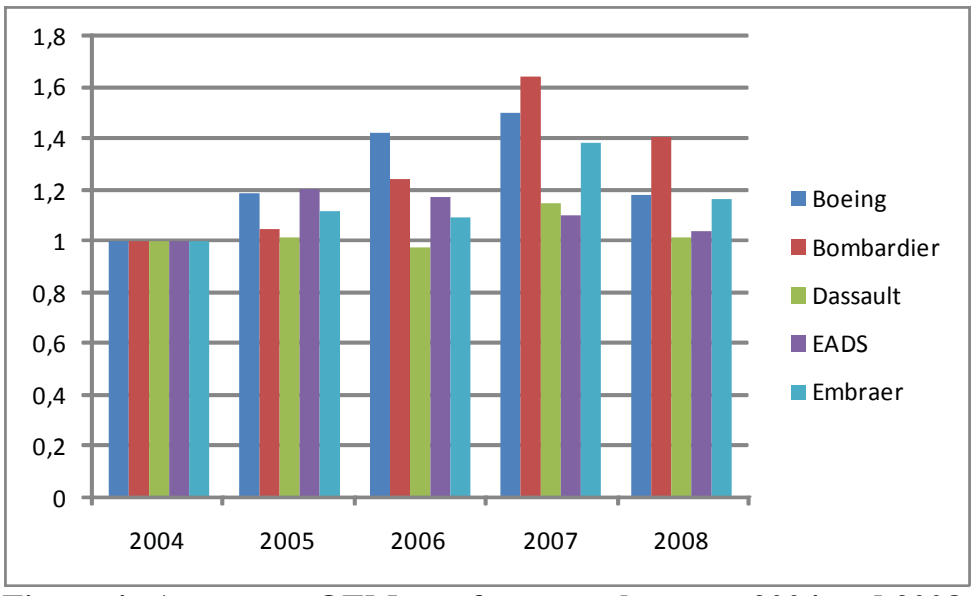

Figure 4. Aerospace OEMs performance between 2004 and 2008

American Institute of Aeronautics and Astronautics 
One can see how all companies start off with the same starting position of $\mathrm{IP}=1$ in 2004 . After one year, EADS and Boeing have climbed the most, but whereas Boeing continues its climb after that, EADS falls back a bit every subsequent year, only to end up at about the same position as it started with in 2008. Boeing and Bombardier both reach a high peak in 2007, but fall back a bit after 2008, as do all companies, making this likely to be an effect of the current financial crisis. Dassault is a company that does not seem to do much. It goes down and up a tiny bit and ends 2008 with an IP of 1.0137, hardly higher than one.

As some final remarks, a company performance measurement model has now been introduced and illustrated. However, the determination of the linear equation's constants could not be performed accurately due to a lack of available data for aerospace OEMs. The influence of the proposed variables on each other is therefore not as well researched as it was for the automotive industry. Moreover, the variables taken were deduced from the automotive industry, making the results valid only under the explicit assumption that these variables are also the best representatives of the five performance pillars for the aerospace industry. Given the lack of available data and companies, it could not be assessed whether or not this is actually a valid assumption or not.

\section{Conclusion}

The research question posed was given as: Can a new performance measurement methodology be developed, based on value creation, co-innovation and lean enterprise theory, that will allow the assessment of aerospace companies' health from a value creation, an engineering and a financial point of view?

The answer to this question is not straightforwardly "yes". It was shown that, at least for the automotive industry, some of the proposed variables are correlated for stably performing companies and that these variables have the power to provide an insight into the different aspects of company performance; competition performance, financial performance, manufacturing capability, innovation capability and supply chain relationships. In the end, all this was integrated into a linear performance measurement model in which each of the five performance pillars is represented by one variable. Were it for the automotive industry, then the answer to the research question would have been "yes". However, when a translation was made to the aerospace industry, difficulties arose. Precisely the reason why it was decided to perform the bulk of the research on the automotive industry made it difficult to adapt the model for aerospace application; the fact that only a few publicly owned aircraft builders exist in the world and that data availability for these companies is rather low. This caused the determination of the precise equation for aircraft builders to be inaccurate and made it very difficult to validate the results. In conclusion, one can therefore say that it is "probably" possible that the devised model is also applicable to the aerospace industry, but that the model as it is now is not yet sufficiently well researched to provide accurate results. For both the automotive industry and the aerospace industry the proposed model takes into account all five of the identified pillars of company performance. Together, these pillars span the range between the "value creation, engineering and financial" points of view mentioned in the research question. The full answer to the research question thus is: "yes, this is possible, but it is particularly hard for the aerospace industry and the attempts made so far cannot be considered accurate enough". More research is required to improve the model's functioning for application to aerospace companies.

\section{Limitations and Recommendations for Further Research}

The largest limiting factor to this research has already been discussed in the foregoing. Data availability for the aerospace OEMs is so low that the results are not very accurate. However, even for the automotive OEMs the amount of data available poses a problem. The fact that, for many companies, data was only available for fewer than ten financial years made that any correlation and regression analyses performed were only able to detect the strongest of effects. This statement is supported by the fact that for those companies for which data of more financial years was available weaker correlations could be found with significance. This makes it worthwhile for future research to continue the collection of data and to again look at the behavior and relations of variables a few years from now, when more data is available. More than fifteen data points per company would be a good place to start. When continuing the collection of data, it is particularly important to do this on a yearly basis. The reason for this is that most companies only keep their annual reports available online for a few years. Moreover, some Japanese companies only specify certain data, like their number of employees and the number of sold vehicles, on their website and only for the last financial year. One year later such data can then no longer be retrieved. This is in fact the reason why only two data points are available for Suzuki.

Secondly, there is the explicit assumption that those variables that work for the automotive OEMs also work for the aerospace companies (excluding V/C of course). At this point, variables' interrelations and behavior for the aerospace industry could not be investigated due to the shortage of data, but for the future, when more aerospace

13

American Institute of Aeronautics and Astronautics 
data is available, it is recommended that the full analysis for variables is also performed for the aerospace companies.

Next, in this research only the aerospace OEMs of civil aircraft were investigated, although most of these also produce military aircraft. Given the diverse nature of the aerospace industry, it is recommended that future research takes a broader look and also investigates other aerospace companies, such as Northrop-Grumman and LockheedMartin, that produce only military hardware, companies, such as Finmeccanica, Raytheon and Textron, that can be considered to be primarily aerospace suppliers, and companies, such as Rolls-Royce, General Electric and Pratt \& Whitney, that build aircraft engines. Doing so will increase the amount of available data and the number of companies, although it should be noted that this makes a very diverse sample that makes company-to-company comparisons something to be done with caution. Going back more into the research' theory, one should consider the proposed variables and their meaning. It is recommended that more research is directed at what each of the proposed variables says. This is in particular aimed at R\&D/C and T/C. For the first one it should be assessed how R\&D/C relates to the actual innovation capabilities. Just spending money does not necessarily make successful innovation. Furthermore, R\&D/C does not capture any possible outsourcing of R\&D efforts. As for T/C, in this research it was, following the research by Beelaerts van Blokland ${ }^{3}$ taken as a measure for the efficiency of the supply chain configuration in creating value. However, no further research has been performed on this. In the future it should be assessed how well T/C actually captures the supply chain relationships part of performance. As stated, this research was performed based on publicly available data. This does however mean that the exact company processes that lead to value creation were not investigated. The question is how more understanding of company processes can be obtained in order to better understand their influence on each of the five pillars of company performance. If future research can be performed in-house of companies, perhaps such understanding could even ultimately lead to the discovery and proof of causal relationships between different processes and between different variables.

Finally, there is the issue of validation. Given the fact that a new model is defined for the calculation of company performance, validation is a difficult issue. The analysis already compared the automotive results to some of the recent automotive development covered in the news. However, this cannot be considered very objective. Future research should therefore attempt to find validation for the accuracy of the model. This could for example be done by comparing the model's results to expert opinions, more news coverage, other metrics of company performance and share price developments. That said, it is clear that the research and the results provide ample evidence that a new company performance valuation method can be set up, but also that a considerable amount of future research is needed before this method can be employed as a replacement of some of the current measures of company performance. There is much work left to be done.

\section{References}

${ }^{1}$ Aune, T.B., \& Gressetvold, E., "Innovating through suppliers: a network approach" International Marketing and Purchasing Group Conference. IMP Group, Manchester, 2007.

${ }^{2}$ Beelaerts van Blokland, W.W., Value chain innovation processes and the influence of co-innovation, Delft University of Technology, Delft, 2006.

${ }^{3}$ Beelaerts van Blokland, W.W. Value leverage (PhD dissertation). Delft: Delft University of Technology, 2010.

${ }^{4}$ Beelaerts van Blokland, W.W., Bulato, F., Elferink, N. H., \& Santema, S. C., "Using lean performance metrics: benchmarking the aerospace industry with the automotive industry," Productions and Operations Management Society (POMS) Conference, Orlando, FL, 2009.

${ }^{5}$ Beelaerts van Blokland, W. W., Fiksiński, M. A., Amoa, S. O., \& Santema, S. C., "The lean value network system: coinvestment and co-innovation as drivers for a sustainable position in the marketplace," International Marketing and Purchasing Group Conference, IMP Group, Manchester, 2007.

${ }^{6}$ Chesbrough, H., Open innovation: the new imperative for creating and profiting from technology, Harvard Business School Press, Cambridge MA, 2003.

${ }^{7}$ Field, A., Discovering statistics using SPSS, Sage Publications Ltd, London, 2009.

${ }^{8}$ Gelei, A., "Taxonomy of supplier firms in the Hungarian automotive industry: aligning customer value and the capability based approach," International Marketing and Purchasing Group Conference, IMP Group, Manchester, 2007..

${ }^{9}$ Hagberg-Andersson, A., Virtanen, H., \& Kock, S., "Dyadic cooperation and relationship effects: an empiral study," International Marketing and Purchasing Group Conference, IMP Group, Manchester, 2007.

${ }^{10}$ Hamel, G., \& Prahalad, C. K., Competing for the future, Harvard Business School Press, Boston, 1994.

${ }^{11}$ Harmsen, H., \& Jensen, B., "Identifying the determinants of value creation in the market: A competence-based approach," Journal of Business Research, Vol. 57, No. 5, 2004, pp. 533-547.

${ }^{12}$ Lamming, R.C., Beyond partnership: strategies for innovation and lean supply, Prentice-Hall, London, 1993.

${ }^{13}$ Lee, H. L., Padmanabhan, V., \& Whang, S., "The bullwhip effect in supply chains," Sloan Management Review, Vol. 38, No. 3, 1997, pp. 93-102. 
${ }^{14}$ Milmo, D., "Volkswagen-Porsche overtakes Toyota as world's largest carmaker," Guardian, URL:: http://www.guardian.co.uk/business/2009/nov/09/volkswagen-porsche-overtakes-toyota-largest-carmaker [cited 12 January 2010]

${ }^{15}$ Murman, E., Allen, T., Bozdogan, K., Cutcher-Gershenfeld, J., McManus, H., Nightingale, D., Lean enterprise value, Palgrave, New York, 2002.

${ }^{16}$ OICA, World motor vehicle production. World ranking of manufacturers, year 2007, International Organization of Motor Vehicle Manufacturers, Paris, 2008.

${ }^{17}$ Parasuraman, A., Zeithaml, V., \& Berry, L., "A conceptual model of service quality and its implications for future research,” Journal of Marketing, Vol. 49, No. 4, 1985, pp. 33-46.

${ }^{18}$ Prahalad, C. K., \& Ramaswamy, V., The future of competition, Harvard Business School Press, Boston, 2001.

${ }^{19}$ The Economist, Toyota: losing its shine URL: http://www.economist.com/opinion/displaystory.cfm?story_id=15064411 [cited 12 January 2010].

${ }^{20}$ Tseng, F.-M., Chiu, Y.-J., \& Chen, J.-S., "Measuring business performance in the high-tech manufacturing industry: a case study of Taiwan's large-sized TFT-LCD panel companies," Omega: The International Journal of Management Science, Vol. 37, Iss. 3, 2009, pp. 686-697.

${ }^{21}$ U.S. Securities and Exchange Commission, URL: http://www.sec.gov/ [cited 22 September 2009].

${ }^{22}$ Verwaal, E., Commandeur, H. R., \& Verbeke, W., "Value creation and value claiming in strategic outsourcing decisions: a resource-contingency perspective," Journal of Management, Vol. 35, No. 2, 2009, pp. 420-444.

${ }^{23}$ Womack, J. P., \& Jones, D. T., Lean thinking: banish waste and create wealth in your organization,Free Press, New York, 2003.

${ }^{24}$ Womack, J. P., Jones, D. T., \& Roos, D., The machine that changed the world. How lean production revolutionized the global car wars, Simon \& Schuster, London, 2007.

${ }^{25}$ Wharton Research Data Services, 2009, Pennsylvania, US.

${ }^{26}$ Zhang, X., \& Chen, R., "Examining the mechanism of the value co-creation with customers," International Journal of Production Economics, Vol. 116, Iss. 2, 2008, pp. 242-250. 